6 Gass H, Goldstein AS, Ruskin R, Leopold NA. Chronic postmyelogram headache. Arch Neurol 1971; 25: 168-70.

7 Gormley JB. Treatment of post-spinal headache. Anesthesiology 1960; 21: 565-6.

8 Baysinger CL, Menk EJ, Harte E, Middaugh R. The successful treatment of dural puncture headache after failed epidural blood patch. Anesth Analg 1986; 65: 1242-4.

9 Stevens RA, Jorgensen $N$. Successful treatment of dural puncture headache with epidural saline infusion after failure of epidural blood patch. Acta Anaesthesiol Scand 1988; 32: 429-31.

10 Boskovski $N$, Lewinski A. Epidural morphine for the prevention of headache following dural puncture. Anaesthesia 1982; 37: 217-8.

11 Thangathurai $D$, Bowles $H F$, Allen HW, Mikhail MS. Epidural morphine and headache secondary to dural puncture. Anaesthesia 1988; 43; 519.

\section{Clinical, electrical and mechanical correlations during recovery from neuromuscular blockade with vecuronium}

To the Editor:

The recent paper by Dupuis et al. ${ }^{1}$ on the correlation between evoked EMG and MMG train-of-four (TOF) fade and respiratory mechanics following vecuronium represents a valuable addition and extension to the original work of Ali et al. ${ }^{2}$ However, I am not sure that they have proved their conclusion that acceptable levels of TOF recovery differ depending on the monitoring technique. According to their data an EMG TOF ratio of 0.90 is equivalent to an MMG value of 0.72 . (Incidentally their regression equation in Figure 3 is wrong. It should ready $=1.033 \mathrm{x}$ minus 20.605 .) This is almost identical to the data we reported earlier ${ }^{3}$ where the comparable MMG value would have been 0.73 .

However, in both studies EMG data was obtained from the digiti minimi muscle while MMG data represented the adductor pollicis muscle. Dupuis et al. state that the issue of whether data obtained from thenar or hypothenar muscles are similar is beyond the scope of and presumably not relevant to their study. I must respectfully disagree. There is evidence that the digiti minimi are less sensitive to nondepolarizing neuromuscular blockers than the adductor pollicis muscle. ${ }^{3}$ If the level of single twitch depression is less in the hypothenar muscle group than in the adductor pollicis is it not reasonable to suppose that TOF fade will also be less affected in the latter muscle? More recent work ${ }^{4}$ suggests that when EMG and MMG data is recorded simultaneously from the adductor pollicis that the information obtained is interchangeable. Unless EMG and MMG recordings of TOF fade are both taken from the same muscle speculation concerning "acceptable" EMG TOF fade ratios should be taken with some skepticism. Hence, the authors' conclusions relative to the correlation of the EMG fade ratio and respiratory mechanics are valid only for situations where the test muscle was the digiti minimi.

Aaron F. Kopman MD

Department of Anesthesiology

Long Island Jewish Medical Center

New Hyde Park, NY 11042

\section{REFERENCES}

1 Dupuis JY, Martin R, Tétrault JP. Clinical, electrical and mechanical correlations during recovery from NM blockade with vecuronium. Can J Anaesth 1990; 37: 192-6.

2 Ali HH, Wilson RS, Savarese JJ, Kitz RJ. The effect of d-tubocurarine on indirectly elicited train-of-four muscle response and respiratory measurements in humans, $\mathrm{Br} \mathrm{J}$ Anaesth 1975; 47: 570-4.

3 Kopman $A F$. The relationship of evoked electromyographic and mechanical responses following atracurium in humans. Anesthesiology 1985; 63: 208-11.

4 Kopman, $A F$. The effect of resting muscle tension on the dose-effect relationship of d-tubocurarine. Does preload influence the evoked EMG? Anesthesiology; 1988; 69: $1003-5$.

\begin{abstract}
REPLY
We appreciate the interest of Dr. Kopman in our study. As mentioned by him and as described in our paper the electromyographic (EMG) response of the adductor digiti minimi muscle was monitored in the study. Thus, the conclusions of the study apply to the monitoring of that muscle. We can speculate on the differences between EMG monitoring of the hypothenar and thenar muscles but this remains beyond the scope of our investigation.

The relation between the EMG $T_{4} / T_{1}$ and the $M M G T_{4} / T_{1}$ is: $y=1.033 x-20.605$ as is correctly expressed in the results section and we apologize for the + in Figure 3.
\end{abstract}

René Martin MD

Jean-Yves Dupuis MD

Sherbrooke, Quebec 